See discussions, stats, and author profiles for this publication at: https://www.researchgate.net/publication/332134144

\title{
Defining and Testing a Safety Cognition Framework Incorporating Safety Hazard Perception
}

Article in Journal of Construction Engineering and Management · December 2019 DOI: 10.1061/(ASCE)C0.1943-7862.0001718

CITATION

1

8 authors, including:

Zhen Zhen Yin

2 PUBLICATIONS 1 CITATION

SEE PROFILE

Kassim Gidado

University of Brighton

32 PUBLICATIONS 319 CITATIONS

SEE PROFILE
130

Ruoyu Jin

London South Bank University

85 PUBLICATIONS 642 CITATIONS

SEE PROFILE

Noel Painting

University of Brighton

23 PUBLICATIONS 76 CITATIONS

SEE PROFILE

Some of the authors of this publication are also working on these related projects:

Recycled aggregate concrete View project

Utilizing Old Concrete from Demolished Buildings for New Applications in Ningbo View project 
Han Y., Yin Z., Liu J., Jin R.*, Gidado K., Painting N., Yang Y., and Yan L. (2019). "Initiating a Safety Cognition Framework Incorporating Safety Hazard Perception." Journal of Construction Engineering and Management. In Press, DOI: 10.1061/(ASCE)CO.1943-7862.0001718. Accepted for publication on 2 April 2019.

\section{Defining and Testing a Safety Cognition Framework Incorporating Safety Hazard}

\section{Perception}

Yu Han ${ }^{1}$, ZhenzhenYin ${ }^{2}$, Jialun Liu $^{3}$, Ruoyu Jin ${ }^{4}$, Kassim Gidado ${ }^{5}$, Noel Painting ${ }^{6}$, Yang Yang ${ }^{7}$, Libo Yan $^{8}$

\section{Abstract}

There has been insufficient research focusing on checking the reliability of construction employees' hazard perceptions by comparing them to the empirical safety data. There have also been limited studies focusing on how site employees' perceptions could be affected by multiple external and internal influence factors such as worker's experience levels. This study firstly developed a theoretical safety cognitionframework addressing site employees' perceptions towards hazards. Empirical data from China's construction safety report were

\footnotetext{
${ }^{1}$ Associate Professor, Faculty of Civil Engineering and Mechanics, Jiangsu University, 301 Xuefu Road, Zhenjiang, 212013, Jiangsu, China. Email: hanyu85@yeah.net

${ }^{2}$ Graduate research assistant, Faculty of Civil Engineering and Mechanics, Jiangsu University, 301 Xuefu Road, Zhenjiang, 212013, Jiangsu, China.735963289@qq.com

${ }^{3}$ Graduate research assistant, Faculty of Management, Jiangsu University, 301 Xuefu Road, Zhenjiang, 212013, Jiangsu, China. Email: 2553975137@qq.com

${ }^{4}$ Senior Lecturer, School of Environment and Technology, University of Brighton, Cockcroft Building 616, Brighton, BN24GJ, U.K. Email: R.Jin@brighton.ac.uk

${ }^{5}$ Principal Lecturer, School of Environment and Technology, University of Brighton, Cockcroft Building, Brighton, BN24GJ, UK. Email: K.I.Gidado@brighton.ac.uk

${ }^{6}$ Senior Lecturer, School of Environment and Technology, University of Brighton, Cockcroft Building, Brighton, BN24GJ, U.K. Email: N.J.Painting@brighton.ac.uk

${ }^{7}$ Associate Professor,MOE Key Laboratory of New Technology for Construction of Cities in Mountain Area and School of Civil Engineering,Chongqing University, Chongqing, China. Email: yangyangcqu@cqu.edu.cn

${ }^{8}$ Junior Professor, Centre for Light and Environmentally-Friendly Structures, Fraunhofer Wilhelm-KlauditzInstitutWKI, BienroderWeg54E,Braunschweig, Germany. Email: 1.yan@tu-braunschweig.de
} 
collected to quantify and define eight common safety hazard or accident scenes. Following the empirical data analysis, these eight hazards were ranked in terms of their occurrence, severity, and controllability. Based on a total of 201 valid questionnaires received in China's construction industry, site employees' perceptions towards these eight hazards were analyzed, ranked, and compared to the empirical ranking. Major findings included but were not limited to: (1) hazards with higher occurrence tended to be perceived with less deviation; (2) more experienced employees were more likely to apply their prior scenarios and safety knowledge in perceiving given hazards and further to hold more reliable perceptions; (3) prior scenarios might also create biased perceptions in the case of electrocution. The current study contributed to the knowledge in safety climate by proposing and testing the framework incorporating safety perceptions. Continued from this study, further research could be performed to explore more subgroup factors' effects on workers' perceptions, as well as how to design an effective safety training program to correct their biased perceptions.

Keywords:Safety cognition; Safety hazards; Safety perception; Construction Safety; Safety climate

\section{Introduction}

Construction is considered one of the most risky industries in terms of safety performance (Lingard and Rowlinson, 2015). The employment in the construction industry accounted only for $4 \%$ of all workforce on nonfarm payrolls, but accounted for over $17 \%$ of fatal injuries crossing all industries in the U.S. (U.S. Bureau of Labor Statistics., 2013a; 2013b). About 2.9\% of construction workers in UK are injured each year, and the rate is significantly higher than the average value across all industries (Swingewood and Burd, 2018). Organizations (e.g., main contractors) should lead and promote the culture that supports safety and health, which involves a risk-based thinking as well as the participation and consultation of workers (Swingewood and Burd, 2018). Construction risks could come from site hazards, and workers' 
risk perception towards certain safety hazards is not separated from safety culture. OSHA (2011) defined four types of most commonly occurring accidents, namely fall, struck-by, caught-in-between, and electrocution. There have been multiple studies (e.g., Guo et al., 2017; Asilian-Mahabadi et al., 2018; Wang et al., 2018) on workers' safety behavior and safety education on preventing these accidents/incidents from happening. Based on these existing studies, more research could be performed in investigating the perceptions of workers and other site employees' towards these commonly encountering hazards or accidents. Specifically, more studiesare needed to investigate how the feature of the hazard or accident (e.g., its frequency of occurrence) would affect site employees' safety hazard perception, as well as how the site employees' subgroup factors (e.g., site experience level) would impact safety perceptions (Han et al., 2019a).

Li et al. (2017) identified workers' self-perception of safety (e.g., workers' believes in controlling their own safety onsite) as one of the main dimensions of safety climate. However, there has been limited assessment and evaluation of workers' safety perceptions against the empirical data to evaluate the reliability of their perceptions and whether certain training is needed to modify that perception, especially towards commonly encountered site hazards (e.g., fall). Safety perceptions have direct effects on workers' safety behavior. It should also be noticed that construction employees' perceptions could be affected by several potential external and internalinfluence factors, such as the building trades and job positions (Chen and Jin, 2015), the local cultural context (Zou and Zhang, 2009), and demographic factors (Han et al., 2019b). There is a need to understand the perceptions of site employees in order to provide proper safety training or education programs with the goal of promoting a positive safety climate on-site. Understanding how employees' perceptions could be affected by these defined influence factors also enables safety educators to decide how to correct biased safety perceptions. 
Besides the need to study employees' safety perceptions against empirical data, there is also a need to continue the study of subgroup factors linked to safety cognition which would affect employees' perceptions and behaviors in construction safety (Jin et al., 2019). So far there has been limited research further linking employees' safety perceptions towards site hazards to their internal safety cognition pattern.Aiming to address these research gaps of construction employees' safety perceptions towards site hazards, this study was designed with these objectives: (1) to define a theoretical cognition framework incorporating the external and internal factors that affect site employees' safety perceptions within the context of safety culture; (2) to identify the typical safety hazards based on empirical safety accident data; (3) to investigate site employees' safety hazard perceptions by comparing them to the empirical data; (4) to further discuss how the feature of these hazards would affect employees' safety perceptions; and (5) to discuss how the safety cognition patterns, as internal indicators, would affect site employees' hazard perception. This research adopted a comprehensive research methodology, including theoretical cognition framework establishment, questionnaire survey approach to site employees in China's construction industry, statistical analysis involving ranking method, and finally an in-depth qualitative discussion. The study contributed to the body of knowledge in safety perception of construction employees by addressing the reliability of hazard perceptions, as well as investigating how employees' perceptions were affected by the hazard feature as well as their own safety cognition. Safety hazard perception in this study was measured in terms of the given hazard's occurrence, severity, and controllability.

\section{Literature review}

\section{Safety climate and safety culture}

The workplace safety perception is part of safety climate, which reflects site employees' perception regarding the role of safety (Cox and Cox, 1991). Li et al. (2017) studied the 
safety climate in the level of construction team which consisted of workers and foremen. Workers' attitudes to hazards, risks and possibility of injury, capability to identify safety hazards, as well as belief in their own ability to control personal safety onsite were listed by Li et al. (2017) as key indicators for safety climate within construction teams. Safety climate is included in the safety culture, which involves both implicit and explicit social cognitions (Marquardt et al., 2012). Both safety climate and safety culture impact safety performance (Choudhry et al., 2009; Newaz et al., 2018). Both of them are multi-level depending on site employees' job positions (Grote and Kunzler, 2000; Chen and Jin, 2012). Chen and Jin (2015) further identified on construction sites' safety climate from employees with and without management roles, as well as workers from various building trades (e.g., mechanical).

Safety climate can be measured by site employees' safety perceptions (Zohar, 1980; Brown and Homes, 1986). Employees' safety perceptions are formed by their own patterns of safety cognition when exposed to hazards (Liu, 2018). Implicit memory influences and has a significant role in unconscious cognition when making judgements (Jacoby and Witherspoon, 1982; Jacoby et al., 1992). Cognition directly affects human behavior (Liao et al., 2017). Safety cognition for construction personnel is critical to improve safety performance in construction (Chen et al., 2011).

\section{Subgroup factors among constructionsite employees}

Studies on construction safety climate have largely focused on workers' safety perception (Melia et al., 2008), attitudes (Chen and Jin, 2013), safety behaviour (Jin and Chen, 2013), and further how they were linked to safety performance (Molenaar et al., 2009). As safety climate could be divided according to subgroup categories (Schein, 1996), more studies have focused on subgroup or demographic factors of workers and their safety issues. For example, Korkmaz and Park (2018) found that foreign workers did not have the same safety beliefs or commitments towards safety management compared to domestic workers in Korea. It was 
further suggested that an improved safety education was needed to improve foreign workers' safety perceptions (Korkmaz and Park, 2018). Similarly, del Puerto et al. (2013) identified that Hispanic workers in the U.S. construction industry tended to hold the belief that productivity and work quality is more important than safety. Besides these demographic

122 factors, other internal factors also had some significant influences on site employees' safety perceptions. For example, Han et al. (2019a) found that construction site employees in their mid-career (i.e., with more than five years' site experience) were more likely to underestimate the severity of site hazards compared to their entry-level peers. It was further indicated of the importance of proper safety training in correcting site employees' biased 127 perceptions.

\section{Theoretical background}

This empirical study of construction employees' safety perceptions towards given site hazard/scenarios started from the defined theoretical cognition framework illustrated in Fig.1.

The framework was set in the context of safety culture which was defined byMarquardt et al. (2012) with three different layers of social cognition. As indicated by Marquardt et al. (2012), explicit attitudes towards certain safety hazards could be deemed as part of safety climate.

\section{$<$ Insert Fig.1 here $>$}

The core structure of safety cognition within safety culture model shown in Fig.1 is based on multiple theories proposed from earlier research including Schein (1992), Guyldenmund 137 (2000), Rowatt et al. (2005), Parker et al.(2006), and Marquardt et al. (2012). Other previous studies are also reflected in Fig.1. For example, appraisal of work hazards forms part of safety climate (Mohamed, 2002; Saunders et al., 2017). According to Fig.1, multiple factors affect workers' individual perceptions towards certain given site hazard scenarios, including both internal and external factors. These inter-related factors are illustrated in Fig.1. For example, prior similar scenarios of safety accidents, either from workers own witness or 
secondary experience from peers would form their own safety knowledge. Safety knowledge, 144 prior scenarios, and workers' own basic assumptions (Marquardt et al., 2012) work as internal factors that stimulate their perceptions towards certain site hazards (e.g., fall from working at height). Other internal factors include demographic issues such as workers' age and gender (Han et al., 2019b), as well as workers' years of working experience (Han et al., 2019a). External factors such as features of hazards (i.e., occurrence, severity, and controllability) described by Han et al. (2019a) could also affect individual perceptions. Fig.1 also reveals the role of safety training in correcting employees' biased or deviated hazard perceptions. The process of how workers perceive site hazards can be described in Fig.2. $<$ Insert Fig. 2 here $>$ workers' judgement or perceptions when exposed to certain site hazards. The prior scenarios form workers' implicit cognition in safety culture, which then affects workers' basic assumption towards site hazards. Prior scenarios also form workers' knowledge in safety in Fig.3.

Based on Fig.1, Fig.2, and Fig.3, the main research tasks performed in this study are illustrated in Fig.4.

In this research, construction employees' perceptions towards certain given safety hazards are compared to the empirical data to explore the deviation between site employees' perceptions and the reported safety accident data. The three main safety cognition patterns illustrated in Fig.3 are discussed of their effects in workers' perceptions towards certain given 
hazards. The effect of employees' experience level on safety perceptions is also investigated leading to further discussions of how safety training could be implemented effectively to employees by considering these internal influence factors (e.g., site experience).Fig.4 also indicates that employees' experience is reflected through their cognition pattern.

\section{Methodology}

Following the theoretical background and research tasks illustrated from Fig.1 to Fig.4, the overall methodology of this study is demonstrated in Fig.5.

$$
<\text { Insert Fig. } 5 \text { here }>
$$

According to Fig.5, this study was based on a four-step approach, namely collecting the empirical data of safety accidents/hazards, site investigation through questionnaire survey to construction employees, follow-up statistical analysis, and the in-depth discussion of safety cognition illustrated in Fig.2 and Fig.3. The statistical methods included both descriptive way (e.g., ranking method) and inferential method to allow comparisons of: (1) the empirical safety data and employees' perception-based data related to safety accidents, and (2) the comparison of perceptions between more experienced employees and their less experienced peers towards given safety accident/hazard scenes. More detailed descriptions of research steps can be found below.

\section{Empirical safety accident data}

According to Fig.1, the consistency between workers' perceptions and empirical data regarding safety hazards would allow the further decisions in safety management on whether training is needed to correct biased perceptions. Researchers in this study started from the empirical data of eight most commonly encountered accidents in China's construction sites released by Division of Safety Supervision (2017). Researchers ranked the eight different types of hazards according to their occurrence, severity, and risk controllability as shown in Table 1. Moredetails of the eight defined hazards are provided in Table 1. 
Each accident in Table 1 is calculated of its percentage accounting for the total number of accidents reported from 2014 to 2017 in Chinese construction industry. The rankings inter of occurrence and severity among the eight hazards were based on their percentages and fatality rate. The risk score (RS) of each accident is then measured in this study by multiplying the percentage by the fatality rate (Wu et al., 2019). For example, the RS of falling from working at height would be 0.567 . The risk controllability ranking of each corresponding hazard leading to the accident is determined in the reverse order of its RS (i.e. a hazard with higher RS would be ranked lower in its controllability).

Following the data analysis of the eight most typical accidents, two main research questions were proposed: (1) were there deviations or inconsistencies regarding the occurrence, severity, and controllability for the eight hazard/accident scenes between site employees' perceptions and the empirical data summarized in Table 1? (2) would site employees' perceptions be affected by their internal factors such as work experience level as indicated in Fig.1? The follow-up research adopted site investigationto construction employees' in China.

\section{Questionnaire survey}

According to Marquardt et al. (2012), employees' attitudes could be measured by multiitem self-report scales within safety culture. A questionnaire survey, as a typical approach in the study of safety climate and safety culture (Choudhry et al., 2007; Chen and Jin, 2015), was adopted as the research method to collect hazard perceptions from site employees. The questionnaire survey was comprised of two main parts. The first part focused on site employee's demographic information, including their site position (e.g., crew foremen or workers), their building trades (e.g., plumbing), and their years of site experience. The second part was a Likert-scale question consisting of the eight hazard or accident scenes defined in 
Table 1. Following the questionnaire formatting procedure described in the study of Han et al. (2019a) by considering the lower education level completed by most Chinese construction workers, corresponding hazard or accident scenes as shown in Fig.6 were provided to potential survey participants from construction employees.

$<$ Insert Fig. 6 here $>$

For each picture shown in Fig.6, potential survey participants would be asked to rank its occurrence, severity, and controllability.Construability was defined as employees' perceptions of their own capability of holding the given site hazard under control. They were asked the standard questions which were designed to be easily understood by site employees. These three questions were asked for each given hazard/accident scene in the Likert-scale format, including: (1) "how often do you think this hazard happens on-site?"(1: least often; 2: not very often; 3: neutral; 4: quite often; 5: most often); (2) "how dangerous do you think if this hazard happens on-site?" (1: not dangerous at all; 2: not very dangerous; 3 : neutral; 4: quite dangerous; 5: very dangerous); and(3) "how confident do you perceive yourself on holding this hazard under control on-site?" (1: I am totally unable to control it; 2: I am less likely to hold it under my control; 3: neutral; 4: I have some level of confidence to hold it in control; 5: I am very capable of controlling it);

The initial questionnaire underwent the pilot study by being peer reviewed by two site mangers and crew members in Zhenjiang China during August 2017. The questionnaire was then finalized in September 2017 to ensure that questions were all clear to potential participants. The formal sampling of survey participants from construction sites followed the un-biased sampling procedure suggested by Li et al. (2018).During October and December 2017, the finalized questionnaire was sent through construction site visits in south-eastern part of China (e.g., Jiangsu Province and Shanghai Metropolitan regions). Construction employees recruited for the questionnaire survey during site visits were first explained of the 
research purpose and the anonymous nature of the survey by the research team consisting of research students and academic staff. Coordinated by site managers, they were also given the guide that they could either decline the survey request or accept to start the survey by providing the answers to their best knowledge. They were also made aware that they could drop the survey in the middle of filling the questionnaire.

\section{Statistical analysisand in-depth qualitative discussion}

A follow-up statistical analysis was conducted to analyze site employees' perceptions towards the occurrence, severity, and controllability of each given hazard scene. Besides mean and standard deviation as the prescriptive measurements, statistical methods applied in the survey data analysis also included Relative Importance Index (RII), Cronbach's Alpha analysis (Cronbach, 1951), and two-sample $t$-test, the latter two of which were considered inferential statistical methods according to Web Center for Social Research Methods (2006).

The RIIwas used to rank the eight hazard scenes in terms of either occurrence, severity, or controllability. It was calculated following the same equation suggested by Tam (2009) and Eadie et al. (2013). Ranging from 0 to 1, a higher RII value would indicate a higher ranking or a higher degree of significance of the given hazard scene.

Cronbach's Alpha, an internal consistency measurement proposed by (Cronbach, 1951), was adopted in this research to analyze site employees' perceptions among the eight hazard scenes. The Cronbach's Alpha value ranges from 0 to 1 , and a higher value indicates that a site employee who selects one Liker-scale score to one hazard scene would be more likely to assign a similar score to another scene. It was suggested by Nunnally and Bernstein (1994) as well as Bland and Altman (1997) that a Cronbach's Alpha value between 0.70 and 0.95 would be acceptable. Besides the overall Cronbach's Alpha value, there was an individual value corresponding to each hazard scene. An individual Cronbach's Alpha value lower than the overall one indicates that the given hazard scene contributes to the internal consistency. 
Otherwise, a higher individual Cronbach's Alpha value than the overall value means that site employees tended to held a different perception towards this given hazard/accident scene as they would perceive other hazard scenes. There is also an item-total correlation corresponding to each individual Cronbach's Alpha value, measuring the correlation between survey participants' perceptions towards this given hazard scene and their perceptions towards the remaining hazards.

The overall site employees sample was then divided into two subsamples between those having less than five years' site experience and the other with more than five-year experience.The rationale of defining five years' site experience as the cut-off point for subgroup comparison was based on the earlier study by Han et al. (2019a) investigating construction site employees' perceptions towards the danger of common site hazards. It was discovered that employees with less than five years' experience tended to perceive a higher degree of danger compared to their peers in the mid-career stages. The five-year threshold was also confirmed during the pilot study, asconstruction management personnel agreed that site employees with more than five years' experience could be considered as the subgroup of "being more experienced". The two-sample $t$-test was adopted as the parametric method to study the effect of site experience on employees' safety perception towards the given hazard scene. The superior robustness of parametric methods over non-parametric approach was demonstrated by Sullivan and Artino (2013). Other studies such as Carifio and Perla (2008) and Norman (2010) showed that parametric methods are robust for small-sized or nonnormally distributed survey samples. The two sample $t$-test in this study was based on the 5\% level of significance, and the null hypothesis that site experience below or above five years did not have significant effects on employees' perceptions towards the given hazard or accident scene. A $p$ value would be computed corresponding to the $t$ value towards each hazard scene. A $p$ value lower than 0.05 would decline the null hypothesis and suggest the 
alternative hypothesis that employees held significantly different perceptions towards the given hazard scene.

Since employees' perceptions towards each hazard were further categorized as occurrence, severity, and controllability, the ranking deviation for each hazard between employees' perception and the empirical ranking from Table 1 would be calculated and compared in order to identify which hazards cause more deviations. Further qualitative discussions were provided to discuss the possible causes of the deviation of employees' perceptions from the empirical data, leading to suggestions to minimize employee's perception bias through effective safety training.

Similar to the survey sample in Li et al. (2018), construction teams consisting of crew leader and workers were the main survey population. By the end of December 2017, a total of 201 valid responses were collected from totally 290 questionnaires completed through jobsite survey. Among the 201 responses, $85 \%$ were workers from multiple building trades including steel and concrete. The remaining $15 \%$ were foremen or other site personnel with certain management roles. Around $60 \%$ of survey participants had over five years of site experience. The detailed sample attributes are summarized in Table 2.

$<$ Insert Table 2 here $>$

\section{Results}

Site employees' perceptions towards the occurrence, severity, and risk controllability of each of the eight hazards were statistically analyzedand compared to the empirical data according to Division of Safety Supervision (2017).

\section{Statistical analysis of site employees' perceptions towards hazards'occurrence} Following the statistical methods described in Section 4, site employees' perceptions towards the eight hazards were analyzed in terms of occurrence as shown in Tables 3 . The 
mean value and standard deviation in Table 3 were computed based on the five-point Likertscale.

$<$ Insert Table 3 here $>$

The Cronbach's Alpha value over 0.8800 indicated a fairly excellentinternal consistency among the eight hazards. However, the individual value of $\mathrm{H} 2$ related to fall from working at height higher than the overall Cronbach's Alpha value indicated that survey participants from the overall sample tended to perceive $\mathrm{H} 2$ differently as they would perceive the occurrence of other hazards. Fall has been identified in the construction industry worldwide (e.g., OSHA, 2011; Zhang et al., 2015) as most frequently encountered safety hazard.The statistical results showed the consistency in light of the fall hazard occurrence between employees' perceptions and the empirical data in Table 1. It was also found that fall (i.e., H2) ranked top among the eight hazard scenes, with the lowest item-total correlation coefficient. The overall survey population was then divided into two sub-samples according to their site experience level (i.e., below or above five-year site experience). Table 4 summarizes the two-sample $t$-test results. $<$ Insert Table 4 here $>$

According to Table 4, all the eight hazards received significantly different perceptions between less-experienced and more experienced employees in terms of the hazard occurrence. It is seen in Table 4 that those with more than five years' site experience perceived all the eight hazards with higher occurrence. Nevertheless, the two subsamples identified the same three top-ranked hazards (i.e., fall, struck-by, and injuries caused by heavy equipment) with highest occurrence. Among the top-ranked three hazards, two of them (i.e., fall and struck-by) were consistent with the empirical ranking in Table 1. Fig.7 further compares the rankings in terms of occurrence to each hazard scene among the empirical data, the overall sample, subsample with those having more than five-year experience, and subsample with less than five years' experience. Except fall and struck-by which received more consistent perceptions 
342 from subsamples, other hazards were perceived more differently, either between subsamples, or between the empirical data and employee perceptions.

Employees with more than five-year site experience tended to have less deviated perceptions from the empirical data. For example, they held generally reliable perception of viewing structural collapse as one of the frequently occurring accidents, while the less experienced employees tended to significantly underestimate the occurrence of structural collapse. Other hazards perceived by less experienced employees with significant deviations included $\mathrm{H} 7$ related to site vehicles and $\mathrm{H} 8$ related to suffocation or poising.

\section{Statistical analysis of site employees' perceptions towards hazards' severity}

For the same eight defined hazards or accident scenes, the same statistical methods were applied. The overall Cronbach's Alpha value at 0.8620 displayed in Table 5 indicated an excellent internal consistency.

The individual Cronbach's Alpha value for H1 indicated that employees' perceptions towards structural collapse tended to differ as they would perceive other hazards. Electrocution was ranked as the most severe hazard, while hit by site vehicles were perceived least severe. The subgroup difference is summarized in Table 6 , based on the two-sample $t$ test.

Compared to the occurrence, where all hazards were found with significant differences, only one hazard (i.e., H4) was perceived differently between less experienced employees and their more experienced peers. Those with less than five-year experience perceived electrocution significantly more severe. The rankings between samples are further summarized in Fig.7. 
It is seen in Fig.7 that H4 (i.e., electrocution) is significantly overestimated of its severity

fall could occur in different scenarios. For example, employees working at height could fall from a platform lower than 3 meters, or from five-story height. The variety of scenarios in the fall hazard created a varied perception among employees, and hence causing the significant deviation from the empirical ranking. Hazards including $\mathrm{H} 6$ and $\mathrm{H} 7$ were underestimated by employees in terms of their severities, possibly due to the fact that heavy equipment and site vehicles were most commonly seen in their daily work, and they had received relatively more safety training handling heavy equipment and site vehicles. The familiarity could cause employees' underestimate of risks towards site hazards.

Statistical analysis of site employees' perceptions towards hazards' controllability

The last category of hazard perception focused on the controllability. As summarized in Table 7, there is an excellent internal consistency based on the overall Cronbach's Alpha value at 0.8638 .

The individual Cronbach's Alpha value for $\mathrm{H} 1$ higher than the overall one indicated that employees held a differed view towards the controllability of structural collapse. Generally consistent to the risk controllability ranking in Table 1, structural collapse was identified as one of the least controllable hazard. Electrocution, although perceived with the highest degree of severity by the overall sample, was also ranked as the most controllable hazard. The subgroup analysis is summarized in Table 8.

Five out of the eight hazards were perceived by employees with significant differences in in terms of their controllability. Those more experienced employees held a more positive 
view of holding these hazards under control: structural collapse, struck-by, injureis by heavy equipment, hit by site vehicles, and suffocation, choking, or poising. More experienced employees were found with more confidence in controling hazards. The deviation analysis based on rankings is summarized in Fig.9.

$$
<\text { Insert Fig.9 here }>
$$

Fig.9 indicates that compared to their senior peers, less experienced workers tended to have a larger deviation of hazard perception in terms of controlability. Especially for structual collapse and fall, less experienced employees tended to overestimate their capacities to control.

\section{Overall deviation between the empirical data and site employees' safety perceptions}

The overall deviations bewteen subsamples, as well as between employee perceptions and the empirical data are summarized in Fig.10.

\section{$<$ Insert Fig.10 here >}

It is seen in Fig.10 that employees with more than five-year site experience held less deviated perceptions from the empirical data. In contrast, those less experienced employees tended to have more biased perceptions towards all of these eight commonly encountered hazards, especially in $\mathrm{H} 1$, where those more experienced employees had significantly more reliable perceptions. Those hazards with higher accumulated ranking deviations from the overall sample included $\mathrm{H} 1$ related to structural collapse, $\mathrm{H} 2$ related to fall, $\mathrm{H} 4$ related to electrocution, and $\mathrm{H} 8$ related to suffocation, choking, or poising, which of which had the same accumulated deviation of ranking at 10. For H2 (i.e., fall hazards), the deviated perceptions for both subgroups came from the severity and controllability. Instead, the perception of fall occurrence was highly consistent among subgroups without deviation from the empirical data.

\section{Discussion}



factors included the feature of the hazard itself in terms of occurrence, severity, and controllability which would affect construction employees' perceptions towards the given hazard, further causing the deviation between individual perceptions and the reality. Internal factors included but were not limited to worker's site experience, as well as other demographic factors (e.g., gender).

The perception analysis of the survey sample revealed that among the eight defined hazard scenes, fall could be easily identified by the survey sample in this study as the most frequently occurring site accident.In this study, fall and struck-by related hazards, which were defined by Han et al. (2019a) as hazards with higher occurrence, were also perceived by the survey sample as hazards with top occurrences.In contrast, hazards with lower occurrence, such as structural collapse, were perceived by less experienced employees with significant deviation. It is therefore suggested that effective safety training should consider employees' experience level, as well as categorizing the features of hazards.

Implicit cognition reflects how the past experience affects the performance even though the earlier experience is not remembered, as past experience could mediate the feelings, thoughts, and actions towards social objects (Greenwald and Banaji, 1995). Electrocution, which was least severe hazard, was ranked by the overall sample as the most severe one among the eight defined hazards. This could be due to the fact that electrocution used to be a highly occurring accident due to poor electrical safety setup in China's construction sites. A follow-up discussion with these surveyed employees revealed that most of them had been told by their senior peers or others of the stories of fatalities caused by electrocution on-site. According to Fig.1, the prior scenarios, either from their own witnesses, or from story-telling by others, would affect their safety perceptions and form part of their safety knowledge of 441 pre-assuming that electrocution is extremely dangerous, even though nowadaysthe anti- 
electrocution facility had been significantly improved. Variety in the scenario itself, such as fall, could link employees' past experience from working in different heights. This variety within a scenario would then cause deviation of individual perceptions from the empirical data in reality. Other scenarios, such as working with heavy equipment and site vehicles, due to employees' familiarity with them, tended to be perceived with lower severities.

Significant differences in hazard perceptions were found between more experienced employees and their less experienced counterparts. More experienced construction employees were more likely to have developed their safety cognition, which was reflected through their perceptions towards site hazards.In this study, it was indicated that safety knowledge developed within the subgroup of more experienced employees was found mostly reliable in perceiving safety hazards. This research revealed that site employees with more than fiveyear experience held less deviated perceptions towards site hazards from the empirical data.

This further suggested that prior safety scenarios or established safety knowledge could beone reliable source for construction employees to form their correct perceptions. Instead, alternative multiple ways, such as virtual and augmented reality applications (Li et al., 2018), which could be incorporated as part of effective safety training. current hazard scene to form their perceptions leading to decision making. Less experienced employees were more likely to perceive risks according to their basic assumption with

According to Fig.2 and Fig.3, construction employees formed their hazard perceptions by using their own safety knowledge, prior scenarios, or basic assumption. For more experienced workers, they were more likely to apply their previous scenarios to match the limited safety knowledge or prior scenarios to apply. As a result, hazard perceptions of less experienced employees might be more biased and deviate more from the empirical data. 


\section{Conclusion}

This study defined a theoretical safety cognition framework by addressing construction employees' safety perceptions towards given site hazards within the context of safety culture.

471 The initially defined framework was then applied through site investigations in China's construction industry. Firstly, the empirical safety accident data were collected and analyzed in terms of the occurrence, severity, and controllability. Eight hazard or accident scenes (e.g., fall) were defined through the empirical data analysis. Afterwards, site questionnaire survey was conducted to crew members to collect their perceptions towards the eight hazards/accidents. Employees' perceptions of the eight hazards were ranked and compared to the empirical data. Further, this study investigated the differences between more experienced employees and their less experienced peers in perceiving these hazards. The main findings are summarized below:

- Both external and internal factors affect construction employees' safety perceptions.

481 External factors included the feature of the hazard itself. For example, those with higher frequency of occurrence were more likely to be perceived by employees with less deviation in terms of their occurrences.

- Employees with more site experiencewere more likely to apply their prior scenarios and safety knowledge to formmore reliable perceptions towards given safety hazard. This necessitatedproper safety training for less experienced employees (e.g., those with less than five years' experience).

- The main differences of perceptions between more experienced employees and their less experienced peers came from the perception towards the hazard occurrence. In comparison, little difference towards the hazard severity was found between the two subsamples. 
- More experienced employees held more positive views of controlling site hazards with their prior scenarios and developed safety knowledge.

- Although in most cases, gaining experience would help employees develop a less biased hazard perception. Employees' prior scenarios could create biased perceptions towards the severity of certain hazards (e.g., electrocution). It was therefore suggested that experienced workers should also be updated of the latest site condition and safety scenarios.

This research contributes to the body of knowledge in safety culture and safety climate by introducing the theoretical cognition framework incorporating construction employees' hazard perceptions with both external and internal influence factors included and tested through site investigations. Site experience level was identified as one internal factor affecting employees' hazard perceptions. This internal factor divides safety climate into subclimates, and leads to further studies in sub-safety-climate, specifically, how employees from different sub-safety-climate groups could work together to create a positive overall safety climate by minimizing the perception deviations.

The current study was limited to construction employees' safety perceptions towards defined hazards in China, and the experience level was considered the sole variable in studying the variations between site employees. Future studies could extend the defined theoretical framework into other countries' context, and to explore the safety perceptions of immigration or ethnic minority workers. More studies are also needed to how to adopt effective safety education to correct employees' biased perceptions.

\section{Data Availability Statement}

Data generated or analyzed during the study are available from the corresponding author by request.

\section{Acknowledgement}


and Writing Retreat Fund provided by University of Brighton.

\section{References}

Asilian-Mahabadi, H., Khosravi, Y., Hassanzadeh-Rangi, N., Hajizadeh, E., andBehzadan, A. H. (2018). "Factors affecting unsafe behavior in construction projects: development and validation of a new questionnaire." International Journal of Occupational Safety and Ergonomics, 1-8.

Bland, J. and Altman, D. (1997). "Statistics notes: Cronbach's alpha.” BMJ. doi: http://dx.doi.org/10.1136/bmj.314.7080.572

Brown, R. L., and Holmes, H. (1986). "The use of a factor analytic procedure for assessing the validity of an employee safety climate model." Accid. Anal. Prev., 18(6), 455-470.

Carifio, L., and Perla, R. (2008). "Resolving the 50 year debate around using and misusing Likert scales." Med. Educ., 42(12), 1150-1152.

Chen, Q., and Jin, R. (2012). "Safety4Site commitment to enhance jobsite safety management and performance." J. Constr. Eng. Manage., 138(4), 509-519.

Chen, Q., and Jin, R. (2013). "Multilevel safety culture and climate survey for assessing new safety program.” J. Constr. Eng. Manage., 139(7), 805-817.

Chen, Q., and Jin, R. (2015). “A comparison of subgroup construction workers' perceptions of a safety program."Saf. Sci. 74, 15-26.

Chen, W.T., Lu, C.S., and Huang, Y.H. (2011). "Investigating the safety cognition of Taiwan's construction personnel."Journal of Marine Science and Technology, 19(4), 398408.

Choudhry, R.M., Fang, D., and Lingard, H. (2009). "Measuring Safety Climate of a Construction Company." J. Constr. Eng. Manage., 135(9), 890-899.

Choudhry, R. M., Fang, D., and Mohamed, S. (2007). "The nature of safety culture: A survey of the state-of-the-art." Saf. Sci., 45(10), 993-1012.

Cox, S., and Cox, T. (1991). "The structure of employee attitudes to safety: a European example." Work \& Stress, 5 (2), 93-106.

Cronbach, L. J. (1951). "Coefficient alpha and the internal structure of tests."Psychometrika., 16 (3), 297-334.

Del Puerto, C.L., Clevenger, C.M., Boremann, K., and Gilkey, D.P. (2013). "Exploratory study to identify perceptions of safety and risk among residential latino construction workers as distinct from commercial and heavy civil construction workers." J. Constr. Eng. Manage., 04013048-1.

Division of Safety Supervision, Department of Housing and Urban-Rural Construction in China.,2017. Available via http://sgxxxt.mohurd.gov.cn/Public/AccidentList.aspx, accessed on November $18^{\text {th }}, 2017$ (in Chinese).

Eadie, R., Browne, M., Odeyinka, H., McKeown, C., and McNiff, S. (2013). "BIM implementation throughout the UK construction project lifecycle: An analysis." Autom. Constr., 36, 145-151.

Greenwald, A.G., and Banaji, M.R. (1995). "Implicit social cognition: attitudes, self-esteem, and stereotypes." Psychological Review, 102(1), 4-27. 
Grote, G., and Kunzler, C. (2000). "Diagnosis of safety culture in safety management audits." Saf. Sci., 34(1-3), 131-150.

Guldenmund, F. W. (2000). "The nature of safety culture: A review of theory and research." Safety Science, 34, 215-257.

Guo, H., Yu, Y., Xiang, T., Li, H., and Zhang, D. (2017). "The availability of wearabledevice-based physical data for the measurement of construction workers' psychological status on site: From the perspective of safety management." Autom. Constr., 82, 207-217.

Han, Y., Feng, Z., Zhang, J., Jin, R., and Aboagye-Nimo, E. (2019a). "An Empirical Study of Employees' Safety Perceptions of Site Hazard/Accident Scenes.” J. Constr. Eng. Manage.,145(1): 04018117.

Han,Y., Jin, R., Wood, H, and Yang, T. (2019b). "Investigation of demographic factors in construction employees' safety perceptions." Submitted to KSCE Journal of Civil Engineering.

Jacoby, L. L., Lindsay, D. S., andToth, J. P. (1992). "Unconscious influences revealed: Attention, awareness, and control." American Psychologist, 47. 802-809.

Jacoby, L. L., and Witherspoon, D. (1982). "Remembering without awareness." Canadian Journal of Psychology, 36, 300-324.

Jin, R., and Chen, Q. (2013). "Safety culture: effects of environment, behavior\& person." Professional Safety, 05, 60-70.

Jin, R., Zou, P.X.W., Piroozfar, P., Wood, H., Yang, Y., Yan, L., and Han, Y. (2019). “A science mapping approach based review of construction safety research." Safety. Sci., 113, 285-297.

Korkmaz, S., and Park, D.J. (2018).“'Comparison of Safety Perception between Foreign and Local Workers in the Construction Industry in Republic of Korea."Safety and Health at Work, 9(1), 53-58.

Li, Q., Ji, C., Yuan, J., and Han, R. (2017). "Developing dimensions and key indicators for the safety climate within China's construction teams: A questionnaire survey on construction sites in Nanjing." Safety Sci., 93, 266-276.

Li, X., Yi, W., Chi, H.L., Wang, X., and Chan, A.P.C. (2018). "A critical review of virtual and augmented reality (VR/AR) applications in construction safety." Autom. Constr., 86, 150-162.

Liao, P.-C., Liu, B., Wang, Y., Wang, X., and Ganbat, T. (2017). "Work paradigm as a moderator between cognitive factors and behaviors - A comparison of mechanical and rebar workers." KSCE Journal of Civil Engineering, 21(7), 2514-2525.

Lingard, H., andRowlinson, S. (2015). "Occupational Health and safety in construction management."Spon Press, Oxon, UK.

Liu, J. (2018). "Study on the safety cognition deviation characteristics and formation mechanism of construction workers." Master Thesis. Jiangsu University, Zhenjiang, Jiangsu, China, 12-16.

Marquardt, N., Gades, R., and Robelski, S. (2012). "Implicit social cognition and safety culture."Human Factors and Ergonomics in Manufacturing \& Service Industries, 22 (3) 213-234.

Melia, J., Mearns, K., Silvia, A., Silvia, M., and Luisa Lima, M. (2008). "Safety climate responses and the perceived risk of accidents in the construction industry." Saf. Sci., 46(6), 949-958.

Mohamed, S. (2002). "Safety climate in construction site environments." J. Constr. Eng. Manage., 128 (5), 375-384.

Molenaar, K.R., Park, J.I., and Washington, S. (2009). "Framework for measuring corporate safety culture and its impact on construction safety performance." J. Constr. Eng. Manage., 135(6), 488-496. 
Newaz, M.T., Davis, P.R., Jefferies, M., and Pillay, M. (2018) "Developing a safety climate factor model in construction research and practice: A systematic review identifying future directions for research". Engineering, Construction and Architectural Management, 25 (6), 738-757, https://doi.org/10.1108/ECAM-02-2017-0038.

Norman, G. (2010). "Likert scales, levels of measurement and the 'laws' of statistics." Adv.Health Sci. Edu., 15(5), 625-632.

Nunnally, L. and Bernstein, L. (1994)."Psychometric theory.”McGraw-Hill, Inc., New York. OSHA. (2011). "Construction Focus Four training." U.S. Dept. of Labor, Washington, DC, 〈http://www.osha.gov/dte/outreach/construction/focus_four/index.html〉 (Apr. 13, 2017).

Parker,D., Lawrie, M., and Hudson, P. (2006). "A framework for understanding the development of organisational safety culture."Safety Science, 44, 551-562.

Rowatt,W.C., Franklin, L.M., and Cotton, M. (2005). "Patterns and personality correlates of implicit and explicitattitudes toward Christians and Muslims." Journal for the Scientific Study of Religion, 44, 29-43.

Saunders, L.W., Kleiner, B.M., McCoy, A.P., Ellis, K.P., Smith-Jackson, T., andWernz, C. (2017). "Developing an inter-organizational safety climate instrument for the construction industry." Safety Sci., 98, 17-24.

Schein, E. (1992). “Organisational culture and leadership"(2nd ed.). San Francisco: JosseyBass.

Schein, E. H. (1996). "Three cultures management: The key to organizational learning." Sloan Manage. Rev., 38(1), 9-20.

Smith, E. R. (1990). "Content and process specificity in the effects of prior experiences." In T. K. Srull\& R. S. Wyer (Eds.). Advances in social cognition, 3, 1-60. Hillsdale, NJ: Erlbaum. Smith, E. R. (1994). "Procedural knowledge and processing strategies in social cognition." In R. S. Wyer\&T. K. Srull (Eds.), Handbook of social cognition (2nd ed., 1, 99-151). Hillsdale, NJ: Erlbaum.

Sullivan, G.M., and Artino, A.R. (2013). "Analyzing and interpreting data from Likert-type scales." J Med Educ Curric Dev., 5(4), 541-542.

Swingewood, S., and Burd, A. (2018). "How will ISO 45001 change health and safety?" Construction Manager, CIOB, 44-50.

Tam, V.W.Y. (2009). "Comparing the implementation of concrete recycling in the Australian and Japanese construction industries."J. Clean. Prod., 17(7), 688-702.

U.S. Bureau of Labor Statistics. (2013a). "Fatal occupational injuries by industry and event or exposure, all United States, 2012.” 〈http://stats.bls.gov/iif/oshwc/cfoi/cftb0268.pdf〉 (Feb. 1, 2018).

U.S. Bureau of Labor Statistics. (2013b). "The employment situation-December 2012." 〈http://www.bls.gov/news.release/archives/empsit_01042013.pdf〉 (Feb. 1, 2018).

Wang, D., Wang, X., Xia, N. (2018). "How safety-related stress affects workers' safety behavior: The moderating role of psychological capital." Safety Sci., 103, 247-259.

Web Center for Social Research Methods (2006). "Inferential Statistics." Available via http://www.socialresearchmethods.net/kb/statinf.htm, accessed on 28 Nov 2018.

Wu, P., Xu, Y., Jin, R., Lu, Q., Madgwick, D., and Hancock, C.M. (2019). "Perceptions towards risks involved in off-site construction in the integrated design \& construction project delivery." J. Clean. Prod., 213, 899-914.

Zhang, S., Sulankivi, K., Kiviniemi, M., Romo, I., Eastman, C. M., andTeizer, J. (2015). "BIM-based fall hazard identification and prevention in construction safety planning."Safety science, 72, 31-45.

Zohar, D. (1980). "Safety climate in industrial organizations: Theoretical and applied implications." J. Appl. Psychol., 65(1), 96-102. 
661

662

663

664

665

666

667

668

669

670

671

672

673

674

675

676

677

678

679

680

681

682

683

677

679

Zou, P.X.W., and Zhang, G. (2009). "Comparative study on the perception of construction safety risks in China and Australia." J. Constr. Eng. Manage., 135(7), 620-627.

5

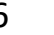

67

68

9

1

3

675

Table 1. Safety data analysis

\begin{tabular}{|c|c|c|c|c|c|c|c|c|}
\hline \multirow[b]{2}{*}{ Type of accidents } & \multirow{2}{*}{$\begin{array}{l}\text { Number } \\
\text { of } \\
\text { accidents }\end{array}$} & \multirow[b]{2}{*}{ Fatality } & \multirow[b]{2}{*}{$\begin{array}{c}\text { Severe } \\
\text { injuries }\end{array}$} & \multirow{2}{*}{$\begin{array}{l}\text { Percen- } \\
\text { tage }\end{array}$} & \multirow{2}{*}{$\begin{array}{l}\text { Fatality } \\
\text { rate per } \\
\text { accident }\end{array}$} & \multicolumn{3}{|c|}{ Ranking } \\
\hline & & & & & & Occurrence & Severity & $\begin{array}{c}\text { Risk } \\
\text { controllability }\end{array}$ \\
\hline Structural collapse & 237 & 454 & 90 & $12 \%$ & 1.92 & 3 & 1 & 7 \\
\hline Falling from & & & & & & 1 & 6 & 8 \\
\hline working at height & 1013 & 1081 & 37 & $53 \%$ & 1.07 & & & \\
\hline Struck-by & 277 & 289 & 8 & $15 \%$ & 1.04 & 2 & 7 & 6 \\
\hline Electrocution & 48 & 50 & 0 & $3 \%$ & 1.04 & 6 & 8 & 3 \\
\hline Injuries by manual & & & & & & 4 & 3 & 5 \\
\hline handling or lifting & 166 & 245 & 34 & $9 \%$ & 1.48 & & & \\
\hline Injuries by heavy & & & & & & 5 & 4 & 4 \\
\hline equipment & 109 & 120 & 17 & $6 \%$ & 1.10 & & & \\
\hline Hit by site vehicles & 27 & 30 & 0 & $1 \%$ & 1.11 & 7 & 5 & 1 \\
\hline $\begin{array}{c}\text { Suffocation, } \\
\text { choking, or poising }\end{array}$ & 20 & 37 & 3 & $1 \%$ & 1.85 & 8 & 2 & 2 \\
\hline
\end{tabular}

684 Note: data in Table 1 were summarized according to accident reports from Division of Safety Supervision (2017) 
Table 2. Sample attributes of the survey population

\begin{tabular}{|c|c|c|c|c|c|c|c|c|}
\hline \multicolumn{2}{|c|}{ Gender } & \multicolumn{2}{|c|}{ Job position } & \multicolumn{2}{|c|}{$\begin{array}{c}\text { Site experience } \\
\text { level }\end{array}$} & \multicolumn{3}{|c|}{ Trade } \\
\hline Male & Female & Workers & $\begin{array}{c}\text { Management } \\
\text { personnel }\end{array}$ & $\begin{array}{c}\text { Less } \\
\text { than five } \\
\text { years }\end{array}$ & $\begin{array}{l}\text { More } \\
\text { than five } \\
\text { years }\end{array}$ & Concrete & Steel/iron & Others* \\
\hline $66 \%$ & $34 \%$ & $85 \%$ & $15 \%$ & $40 \%$ & $60 \%$ & $26 \%$ & $23 \%$ & $51 \%$ \\
\hline
\end{tabular}

Note: other trades include plumbing, electrical, carpentry, and scaffolding, etc. 
Table 3. Statistical analysis of the eight safety hazards measured by occurrence

\begin{tabular}{|c|c|c|c|c|c|c|}
\hline Hazards & $\begin{array}{c}\text { Item-total } \\
\text { Correlation }\end{array}$ & $\begin{array}{c}\text { Cronbach's } \\
\text { Alpha* }\end{array}$ & Mean & $\begin{array}{l}\text { Standard } \\
\text { Deviation } \\
\end{array}$ & $R I I$ & Ranking \\
\hline $\begin{array}{l}\text { H1: (i.e., related to structural } \\
\text { collapse) }\end{array}$ & 0.6169 & 0.8719 & 3.393 & 1.179 & 0.679 & 8 \\
\hline $\begin{array}{l}\mathrm{H} 2 \text { : (i.e. causing falling from } \\
\text { working at height) }\end{array}$ & 0.4184 & 0.8882 & 3.851 & 0.926 & 0.770 & 1 \\
\hline H3: struck-by & 0.7179 & 0.8612 & 3.617 & 1.019 & 0.723 & 3 \\
\hline H4: Electrocution & 0.7223 & 0.8601 & 3.468 & 1.208 & 0.694 & 5 \\
\hline $\begin{array}{l}\text { H5: injuries by manual } \\
\text { handling or lifting }\end{array}$ & 0.7121 & 0.8612 & 3.423 & 1.120 & 0.685 & 7 \\
\hline $\begin{array}{l}\text { H6: injuries by heavy } \\
\text { equipment }\end{array}$ & 0.7417 & 0.8591 & 3.622 & 1.003 & 0.724 & 2 \\
\hline H7: hit by site vehicles & 0.6205 & 0.8707 & 3.453 & 1.053 & 0.691 & 6 \\
\hline $\begin{array}{l}\text { H8: suffocation, choking, or } \\
\text { poising }\end{array}$ & 0.6480 & 0.8680 & 3.473 & 1.030 & 0.695 & 4 \\
\hline
\end{tabular}


779 Table 4. Comparison of perceptions towards the hazards' occurrence between newer and more experienced site employees

\begin{tabular}{|c|c|c|c|c|c|c|c|c|}
\hline \multirow[b]{2}{*}{ Hazards } & \multicolumn{3}{|c|}{$\begin{array}{c}\text { Employees over five-year site } \\
\text { experience }\end{array}$} & \multicolumn{3}{|c|}{$\begin{array}{c}\text { Employees with less than five } \\
\text { years' site experience }\end{array}$} & \multicolumn{2}{|c|}{ Two-sample $t$-test results } \\
\hline & Mean & $\begin{array}{l}\text { Standard } \\
\text { Deviation }\end{array}$ & Ranking & Mean & $\begin{array}{l}\text { Standard } \\
\text { Deviation }\end{array}$ & Ranking & $t$ value & $p$ value \\
\hline H1 & 3.790 & 1.000 & 2 & 2.800 & 1.180 & 8 & 6.13 & $0.000 *$ \\
\hline $\mathrm{H} 2$ & 3.992 & 0.861 & 1 & 3.638 & 0.984 & 1 & 2.62 & 0.010* \\
\hline $\mathrm{H} 3$ & 3.760 & 0.966 & 3 & 3.400 & 1.060 & 3 & 2.44 & $0.016 *$ \\
\hline $\mathrm{H} 4$ & 3.710 & 1.110 & 6 & 3.100 & 1.260 & 5 & 3.52 & $0.001 *$ \\
\hline H5 & 3.730 & 1.020 & 5 & 2.960 & 1.120 & 7 & 4.92 & 0.000* \\
\hline H6 & 3.760 & 1.080 & 3 & 3.413 & 0.837 & 2 & 2.56 & 0.011* \\
\hline $\mathrm{H} 7$ & 3.669 & 0.986 & 7 & 3.130 & 1.070 & 4 & 3.64 & $0.000 *$ \\
\hline $\mathrm{H} 8$ & 3.600 & 1.030 & 8 & 3.270 & 1.010 & 6 & 2.24 & 0.026* \\
\hline
\end{tabular}

$781 *$ :a $p$ value lower than 0.05 indicates significant differences between subgroup workers with different level of site experience. The same rule applies to follow-up tables involving two-sample $t$-test. 
822 Table 5. Statistical analysis of the eight safety hazards measured by severity

\begin{tabular}{lcccccc}
\hline \multicolumn{1}{c}{ Hazards } & $\begin{array}{c}\text { Item-total } \\
\text { Correlation }\end{array}$ & $\begin{array}{c}\text { Cronbach's } \\
\text { Alpha* }\end{array}$ & Mean & $\begin{array}{c}\text { Standard } \\
\text { Deviation }\end{array}$ & RII & Ranking \\
\hline $\begin{array}{l}\text { H1: (i.e., related to structural } \\
\text { collapse) }\end{array}$ & $\mathbf{0 . 4 2 2 5}$ & $\mathbf{0 . 8 6 9 0}$ & 4.030 & 1.072 & 0.806 & 5 \\
$\begin{array}{l}\text { H2: (i.e. causing falling from } \\
\text { working at height) }\end{array}$ & 0.5854 & 0.8479 & 4.154 & 0.895 & 0.831 & 2 \\
$\begin{array}{l}\text { H3: struck-by } \\
\text { H4: Electrocution }\end{array}$ & 0.7134 & 0.8333 & 3.876 & 0.943 & 0.775 & 6 \\
$\begin{array}{l}\text { H5: injuries by manual } \\
\text { handling or lifting }\end{array}$ & 0.6825 & 0.8377 & 4.179 & 0.882 & 0.836 & 1 \\
$\begin{array}{l}\text { H6: injuries by heavy } \\
\text { equipment }\end{array}$ & 0.7042 & 0.8366 & 4.080 & 0.827 & 0.816 & 3 \\
$\begin{array}{l}\text { H7: hit by site vehicles } \\
\begin{array}{l}\text { H8: suffocation, choking, or } \\
\text { poising }\end{array}\end{array} \quad 0.6428$ & 0.8416 & 3.751 & 1.067 & 0.750 & 7 \\
\hline
\end{tabular}


839 Table 6. Comparison of perceptions towards the hazards' severity between newer and more 840 experienced site employees

\begin{tabular}{llccccccc}
\hline & \multicolumn{3}{c}{$\begin{array}{c}\text { Employees with more than five- } \\
\text { year site experience }\end{array}$} & \multicolumn{3}{c}{$\begin{array}{c}\text { Employees with less than five } \\
\text { years' site experience }\end{array}$} & Two-sample t-test results \\
\cline { 2 - 9 } Hazards & Mean & $\begin{array}{c}\text { Standard } \\
\text { Deviation }\end{array}$ & Ranking & Mean & $\begin{array}{c}\text { Standard } \\
\text { Deviation }\end{array}$ & Ranking & t value & p value \\
\hline H1 & 4.070 & 1.020 & 2 & 3.980 & 1.150 & 5 & 0.58 & 0.566 \\
H2 & 4.198 & 0.891 & 1 & 4.088 & 0.903 & 3 & 0.86 & 0.393 \\
H3 & 3.835 & 0.960 & 6 & 3.938 & 0.919 & 6 & -0.76 & 0.447 \\
H4 & 4.066 & 0.946 & 3 & 4.350 & 0.748 & 1 & $-\mathbf{2 . 3 7}$ & $\mathbf{0 . 0 1 9 *}$ \\
H5 & 4.058 & 0.849 & 4 & 4.112 & 0.795 & 2 & -0.46 & 0.643 \\
H6 & 3.830 & 1.140 & 7 & 3.625 & 0.946 & 7 & 1.42 & 0.158 \\
H7 & 3.777 & 0.979 & 8 & 3.490 & 1.110 & 8 & 1.89 & 0.061 \\
H8 & 4.050 & 0.893 & 5 & 4.013 & 0.864 & 4 & 0.29 & 0.769 \\
\hline
\end{tabular}

841 
858 Table 7. Statistical analysis of the eight safety hazards measured by risk controllability

\begin{tabular}{lcccccc}
\hline \multicolumn{1}{c}{ Hazards } & $\begin{array}{c}\text { Item-total } \\
\text { Correlation }\end{array}$ & $\begin{array}{c}\text { Cronbach's } \\
\text { Alpha }\end{array}$ & Mean & $\begin{array}{c}\text { Standard } \\
\text { Deviation }\end{array}$ & RII & Ranking \\
\hline $\begin{array}{l}\text { H1: (i.e., related to structural } \\
\text { collapse) }\end{array}$ & $\mathbf{0 . 4 5 4 0}$ & $\mathbf{0 . 8 6 8 4}$ & 3.055 & 1.242 & 0.611 & 8 \\
$\begin{array}{l}\text { H2: (i.e. causing falling from } \\
\text { working at height) }\end{array}$ & 0.6287 & 0.8462 & 3.622 & 0.947 & 0.724 & 2 \\
$\begin{array}{l}\text { H3: struck-by } \\
\text { H4: Electrocution }\end{array}$ & 0.7208 & 0.8354 & 3.443 & 1.033 & 0.689 & 7 \\
$\begin{array}{l}\text { H5: injuries by manual } \\
\text { handling or lifting }\end{array}$ & 0.6274 & 0.8459 & 3.682 & 1.191 & 0.736 & 1 \\
$\begin{array}{l}\text { H6: injuries by heavy } \\
\text { equipment }\end{array}$ & 0.6135 & 0.8471 & 3.448 & 1.090 & 0.690 & 5 \\
$\begin{array}{l}\text { H7: hit by site vehicles } \\
\text { H8: suffocation, choking, or }\end{array}$ & 0.7199 & 0.8355 & 3.587 & 1.031 & 0.717 & 4 \\
poising & 0.5539 & 0.84535 & 3.622 & 1.018 & 0.724 & 3 \\
\hline
\end{tabular}


876 Table 8. Comparison of perceptions towards the hazards' controllability between newer and

877 more experienced site employees

\begin{tabular}{lcccccccc}
\hline & \multicolumn{3}{c}{$\begin{array}{c}\text { Employees above five-year site } \\
\text { experience }\end{array}$} & \multicolumn{3}{c}{$\begin{array}{c}\text { Employees with less than five } \\
\text { years' site experience }\end{array}$} & Two-sample t-test results \\
\cline { 2 - 9 } Hazards & Mean & $\begin{array}{c}\text { Standard } \\
\text { Deviation }\end{array}$ & Ranking & Mean & $\begin{array}{c}\text { Standard } \\
\text { Deviation }\end{array}$ & Ranking & t value & p value \\
\hline H1 & 3.300 & 1.180 & 8 & 2.690 & 1.250 & 3 & 3.46 & $\mathbf{0 . 0 0 1 *}$ \\
H2 & 3.537 & 0.931 & 6 & 3.750 & 0.961 & 1 & -1.56 & 0.122 \\
H3 & 3.640 & 1.060 & 4 & 3.138 & 0.924 & 8 & $\mathbf{3 . 6 0}$ & $\mathbf{0 . 0 0 0 *}$ \\
H4 & 3.660 & 1.160 & 3 & 3.710 & 1.240 & 2 & -0.29 & 0.769 \\
H5 & 3.450 & 1.100 & 7 & 3.450 & 1.090 & 4 & -0.02 & 0.981 \\
H6 & 3.810 & 0.994 & 1 & 3.250 & 1.000 & 6 & $\mathbf{3 . 8 9}$ & $\mathbf{0 . 0 0 0}^{*}$ \\
H7 & 3.802 & 0.900 & 2 & 3.350 & 1.130 & 5 & $\mathbf{3 . 0 1}$ & $\mathbf{0 . 0 0 3 *}$ \\
H8 & 3.612 & 0.995 & 5 & 3.188 & 0.110 & 7 & $\mathbf{2 . 9 6}$ & $\mathbf{0 . 0 0 4 *}$ \\
\hline
\end{tabular}

